Perspective

\title{
Rare surgical causes of recurrent LRTI
}

Volume 5 Issue 4 - 2016

Pradnya S Bendre, Flavia Henry D'souza, Ramdas Nagargoje, Parag Karkera

Department of Paediatric Surgery, Bai Jerbai Wadia Hospital for Children, India

Correspondence: Flavia Henry D'souza, I Professor, 2Mch Student, Department of Paediatric Surgery, Bai Jerbai Wadia Hospital for Children, India, Email drflaviadsouza@gmail.com

Received: October 14, 2016 | Published: October 18, 2016 population. Besides medical causes there are a few other causes of LRTI where surgically correctable structural malformation is the culprit. It is very important to identify these cases, as rectifying these would mean prevention of catastrophic complications and recurrence of LRTI in these cases. We here by present our experience of surgically curable causes along with few extremely rare conditions which manifested as recurrent LRTI.

Keywords: lower respiratory tract infection, surgical causes

\section{Case reports}

\begin{tabular}{|c|c|c|c|}
\hline Age and Brief History & Clinical Diagnosis & Photograph & Surgery \\
\hline $\begin{array}{l}50 \text { days, recurrent LRTI one episode } \\
\text { of SIDS }\end{array}$ & $\begin{array}{l}\text { Intrathoracic } \\
\text { stomach }\end{array}$ & & Fundoplication and repair of hiatus \\
\hline $\begin{array}{l}7 \text { month, failure to thrive recurrent } \\
\text { abdominal distension }\end{array}$ & $\begin{array}{l}\text { H-type of tarcheo } \\
\text { oesophageal fistula }\end{array}$ & & Repair of $\mathrm{H}$-shape fistula \\
\hline $\begin{array}{l}2 \text { year, recurrent non projectile } \\
\text { vomiting }\end{array}$ & $\begin{array}{l}\text { Microgastria with } \\
\text { megalo-esophagus }\end{array}$ & & $\begin{array}{l}\text { Gastric exclusion with Roux en Y } \\
\text { end to end esophago jejunostomy }\end{array}$ \\
\hline $\begin{array}{l}7 \text { months, three episodes of LRTI } \\
\text { Diagnosed as Right congenital } \\
\text { diaphragmatic hernia }\end{array}$ & $\begin{array}{l}\text { Hepato pulmonary } \\
\text { fusion. }\end{array}$ & & $\begin{array}{l}\text { Right thoracotomy with definite } \\
\text { repair }\end{array}$ \\
\hline 2 Year old male child, recurrent LRTI & Bronchogenic cyst & & Thoracotomy with excision of cyst \\
\hline
\end{tabular}

\section{Discussion}

Lower respiratory tract infections are quiet common in pediatric age group. After retrospectively analysing these cases which we had to intervene we noticed few significant facts i. By the time surgeon is involved patient had undergone numerous investigations and lost significant weight.

ii. Simple measures like putting Ryles tube before taking x-ray chest as well as taking lateral plate would have given clue to anomalies like bronchogenic and neuroenteric cyst. 
iii. More liberal use of ultrasonography chest to locate any space occupying lesion may be a good screening tool.

iv. Barium swallow is better than milk scan as it can diagnose GER as well as rule out Structural anomalies of esophagus like $\mathrm{H}$-shape tracheo-esophageal fistula, adding gastric plates can rule out malrotation and other gastric anomalies.

v. Adding surgeons eye early in evalution can accelerate pick up of surgical causes.

vi. CT has detected almost every surgical cause from common like foreign body to rare like Megaesophagus.

vii. While managing severely malnourished feeding jejunostomy and postpone definitive repair at later date was good make shift.

We suggest following protocol for screening surgical causes. ${ }^{1-4}$

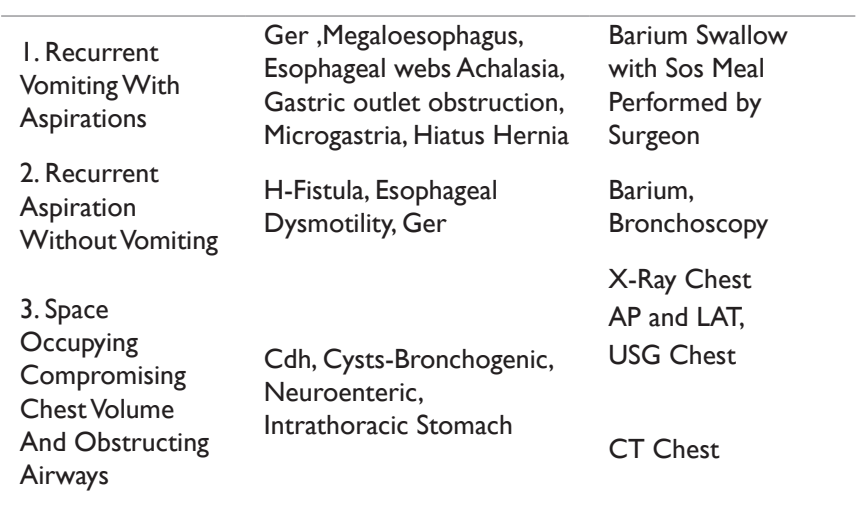

The most common surgical cause for recurrent LRTI

i. GERD

ii. Foreign bodies ${ }^{5}$

Less Common Causes

a. $\mathrm{CCAM}^{6}$

b. $\mathrm{CLE}^{7,8}$

c. Bronchogenic cyst

d. Neuroenteric cyst,

e. Congenital diaphragmatic hernia

Rare Causes

a. Microgastria megaloesophagus syndrome

b. Hepato pulmonary fusion.

c. H-Shape tracheo-esophageal fistula ${ }^{9}$ d. Malrotation of gut and

e. Hiatus hernia with Intrathoracic stomach,

f. Short esophagus with Intrathoracic stomach.

\section{Conclusion}

In all these cases series of investigations were done before referral for surgical intervention early involvement of surgeons would have hastened detection of surgical causes. Malnutrition was a major limiting factor in tolerating major surgery and feeding jejunostomy was an excellent way to improve nutrition and keeping patient symptom free. Aspirations were better manageable than loss of effective volume of thorax. Planned surgery with ventilatory support postoperative will maximise results. ${ }^{10}$

\section{Acknowledgments}

None.

\section{Conflicts of interest}

Authors declare that there is no conflict of interest.

\section{References}

1. Bazrafshan A, Heydarian F, Hashemzadeh A, et al. Surgical causes in lower respiratory tract infection in children. Patient saf qual improve. 2015;3(1):196-197.

2. Kumar A, Bhatnagar V. Respiratory distress in neonates. Indian $J$ Pediatr. 2005;72(5):425-483.

3. Wesenberg RL, Graven SN, McCabe EB. Radiological findings in wet lung disease in the newborn. Radiology. 1971;98(1):69-74.

4. Taylor PM, Allen AC, Stinson DA. Benign unexplained respiratory distress of the newborn. Pediatr Clin North Am. 1971;18(3):975-1004.

5. Metrangelo S, Monetti C, Meneghini L, et al. Eight years' experience with foreign-body aspiration in children: what is really important for a timely diagnosis? J Pediatr Surg. 1999;34(8):1229-1231

6. Moerman P, Gryns, Vanderberyhe K et al. Pathogenesis of CCAM of the lung. Histopathology. 1992;21(4):135-139.

7. Man DW, Handy MH, Hendry GM, et al. Congenital lobar emphysema: problems in diagnosis and management. Arch Dis Child. 1983;58(9):709-712.

8. Coran AG, Drongowski R. Congenital cystic diseases of tracheobronchial tree in infants and children: experience with 44 consecutive cases. Arch Surg. 1994;129(5):521-527.

9. Markowitz RI, Merurio MR, Vahjen GA, et al. Lobar emphysema: the role of CT and V/Q scan. Clin Pediatr. 1989;28(1):19-22.

10. Agarwala S, Bhatnagar V, Bajpai M, et al. Factors for poor results of treatment of esophageal atresia in developing countries. Pediatr Surg Int. 1996;11(5-6):312-315. 